\title{
Ego-identity formation in Black South African young adults
}

\author{
Malose S. Makhubela \\ Department of Psychology, University of Pretoria, South Africa E-mail: silas.makhubela@up.ac.za
}

\begin{abstract}
The study examined aspects of ego-identity development among black African students $(N=104$; males $=42 \%$; females $=58 \%$; mean age $=18.7 \mathrm{yr}$.; $\mathrm{SD}=0.9$ ). They completed an ego-identity development measure. Data was analysed descriptively and also comparatively. Findings indicate that ego-identity development appear to be similar between genders, although relatively higher in males than in females on trust, autonomy, initiative, industry and identity stages. Results challenge the gendered bias discourse impressions regarding the influence of collectivistic cultures on psychosocial development in patriarchal societies.
\end{abstract}

Keywords: ego-identity formation, adolescents, gender differences, culture

Identity formation is a critical psychosocial task for both adolescents and young adults (Arseth, Kroger, \& Martinussen, 2009; Erikson, 1968). Successful maturation within the domains of ego-identity has been found to be related to general well-being and personality development (Busch, 2012; Luyckx, Schwartz, Soenens, Vansteenkiste, \& Goossens, 2010; Schwartz et al., 2010). Ego-identity involves the awareness of being the same person across time and different situations which is due to a stable style of individual ego-functioning (McAdams, 2001). Ego-identity is embedded in social and cultural systems (Luyckx, Goossens, \& Soenens, 2006; Schwartz, 2001).

Research emphasises the importance of both culture and gender with respect to the process, timing and domain of adolescent development (Lee, Beckert, \& Goodrich, 2010). While all cultures have similar human developmental tasks (e.g., identity exploration, industry and autonomy) in the socialisation process, the timing and paths to desired developmental outcomes might differ across cultures (see Beckert, Lee, \& Vaterlaus, 2012; Sheldon et al., 2004; Xia, Xie, Zhou, DeFrain, Meredith, \& Combs, 2004). These different expectations may be linked to a cultural preference to either individualism or collectivism. It may also be associated to cultural expectations related to gender. For example, young people in collectivistic societies rely on an external locus of control and traditional values of interdependence with hierarchical authority (Beckert et al., 2012), and this might influence identity development in that adolescents are socialised to be more obedient and conforming, and less autonomous and independent.

Gender has also been implicated in the development of identity and autonomy in adolescence (Sandhu \& Tung, 2006; Meeus, Van de Schoot, Keijsers, \& Branje, 2012). For instance, patriarchal societies generally have delayed expectations for female behavioural and cognitive autonomy compared to males (Beckert, 2007; Beckert et al., 2012; Zimmer-Gembeck \& Collins, 2003). Ideological identity domain is more developed among males in patriarchal communities than in females, while females have more achievement in interpersonal and relationships domains than males (Branch, 2001; Klimstra, Hale, Raaijmakers, Branje, $\&$ Meeus, 2010; Meeus et al., 2012). There is evidence to suggest that there is lesser foreclosure in Asian girls as compared to boys (see Graf, 2003; Sandhu \& Tung, 2006). Girls were higher than boys on identity achievement and moratorium, and were lower than boys on diffusion.

Gender differences in identity development continues to be of much research interest (e.g., Luyckx, Schwartz, Goossens, Soenens, \& Beyers, 2008), because the moderating effects of gender on adolescent psychosocial development are incompletely understood. Cross-cultural evidence is needed on psychosocial development in the identity domains of trust vs mistrust, autonomy vs shame, initiative vs guilt, industry vs inferiority and identity vs identity diffusion. As previously noted, culture should matter in explaining the contouring or shaping of identity development in males and females. These influences should be stronger among children and young adults especially in traditionalist collectivistic black communities of South Africa.

The present study seeks to examine possible gendered effects on ego-identity formation among black South African adolescents.

\section{Method \\ Participants and measure}

Participants were black African high school students $(n=31)$ and undergraduate students $(n=73)$ in the northern province of South Africa (mean age $=18.7 \mathrm{yr}$.; $\mathrm{SD}=0.9 ;$ years; males $=42 \%$; females $=58 \%)$. They completed an ego-identity measure (Ochse \& Plug, 1986). The measure comprises 59 items covering aspects of a coherent sense of trust, autonomy, initiative, industry and identity (Peacock \& Theron, 2007). The reliability of scores from the measure in the study sample was 0.84 .

\section{Procedure and data analysis}

Permission for the study was granted by the Limpopo Province Department of Education and the University of 
Table 1. Gender differences on ego-identity development

\begin{tabular}{|c|c|c|c|c|c|c|c|c|c|c|}
\hline & \multicolumn{6}{|c|}{ Sex } & \multirow{3}{*}{$\begin{array}{c}95 \% \text { CI for } \\
\text { Mean Difference }\end{array}$} & \multirow{3}{*}{$t$} & \multirow{3}{*}{ df } & \multirow{3}{*}{$p$} \\
\hline & \multicolumn{3}{|c|}{ Male } & \multicolumn{3}{|c|}{ Female } & & & & \\
\hline & $M$ & $\mathrm{SD}$ & $n$ & $M$ & $\mathrm{SD}$ & $n$ & & & & \\
\hline $\begin{array}{l}\text { 1.Overall ego-identity } \\
\text { formation }\end{array}$ & 118.16 & 18.93 & 44 & 115.85 & 18.25 & 60 & $-4.99,9.61$ & 0.63 & 102 & 0.53 \\
\hline 2.Trust & 13.61 & 4.29 & 44 & 13.62 & 3.97 & 60 & $-1.62,1.62$ & -0.01 & 102 & 0.99 \\
\hline 3. Autonomy & 9.45 & 3.46 & 44 & 10.13 & 3.65 & 60 & $-2.08,0.73$ & -0.96 & 102 & 0.34 \\
\hline 4. Initiative & 16.82 & 4.48 & 44 & 17.07 & 4.11 & 60 & $-1.93,1.43$ & -0.29 & 102 & 0.77 \\
\hline 5. Industry & 15.61 & 4.89 & 44 & 16.40 & 4.56 & 60 & $-2.64,1.07$ & -0.84 & 102 & 0.40 \\
\hline 6. Identity & 27.57 & 8.61 & 44 & 28.10 & 7.08 & 60 & $-3.59,2.52$ & -0.34 & 102 & 0.73 \\
\hline
\end{tabular}

$* p=$ not significant

Limpopo. Participation in the study was voluntary, while confidentiality and anonymity were guaranteed. Data were analysed using SPSS 22.0 software.

\section{Results}

Table 1 presents summary statistics by ego-identity formation component and differentiating by gender. The results of the independent sample $t$-test show no statistically significant mean difference in ego-identity development between males $(M=118.16, \mathrm{SD}=18.93, n=44)$ and females $(M=115.85, \mathrm{SD}=18.25, n=60), t(102)=0.63$, $p=0.53$.

According to the results, there were also no significant group differences in all the five domains of ego-identity. The respective statistics are detailed in the table above. It is evident that all the genders performed similarly in almost all the domains.

\section{Discussion}

Results indicate an absence of significant gender differences in ego-identity development among the adolescent South African sample, a finding similar to the one by Alessandria and Nelson (2005) among an American sample of Asian, African, Hispanics/Latinos and White students. This is consistent with Klimstra et al.'s (2010) assertion that due to societal changes, identity formation might be similar between genders. With current trends in globalisation and the South African society becoming more modernised, identity formation between genders might be increasingly similar.

The study has some limitations. Due to its exploratory nature, only a limited sample of students was used, constraining the generalisability of the findings. Future research must increase the sample size and study the pattern of the differences longitudinally and across racial/ethnic groups.

\section{References}

Alessandria, K. P., \& Nelson, E. S. (2005). Identity development and self-esteem of first-generation American college students: An exploratory study. Journal of College Student Development, 46(1), 3-12.

Arseth, A. K., Kroger, J., \& Martinussen, M. (2009). Meta-analytic studies of identity status and the relational issues of attachment and intimacy. Identity, 9, 1-32.

Beckert, T. (2007). Cognitive autonomy and self-evaluation in adolescence: A conceptual investigation and instrument development. North American Journal of Psychology, 9(3), 579-594.
Beckert, T., Lee, C., \& Vaterlaus, J. M. (2012). Differences in adolescent cognitive autonomy with Caucasians and Taiwanese. Survey Research-Method and Application, 28, $7-45$.

Branch, C. W. (2001). The many faces of self: Ego and ethnic identities. The Journal of Genetic Psychology, 162(4), 412-429.

Busch, H. (2012). Challenges and chances: Mediation analytical investigations of antecedents and consequences of the development of identity, intimacy, and generativity (Unpublished Doctoral dissertation). Universität Osnabrück, Germany.

Erikson, E. H. (1968). Identity: youth and crisis. Oxford, England: Norton \& Co.

Graf, S. C. (2003). Cross-cultural study of adolescent identity formation and autonomy within the context of parents-adolescent relationships (Unpublished doctoral dissertation). The Florida State University, Florida.

Klimstra, T. A., Hale, W. W., Raaijmakers, Q. A. W., Branje, S. J. T., \& Meeus, W. H. J. (2010). Identity formation in adolescence: Change or stability? Journal of Youth and Adolescence, 39, 150-162.

McAdams, D. P. (2001). The psychology of life stories. Review of General Psychology, 5, 100-122.

Meeus, W., van de Schoot, R., Keijsers, L., \& Branje, S. (2012). Identity statuses as developmental trajectories: A five-wave longitudinal study in early-to-middle and middleto-late adolescents. Journal of Youth and Adolescence, 41, $1008-1021$.

Lee, C., Beckert, T., \& Goodrich, T. (2010). The relationship between individualistic, collectivistic, and transitional cultural value orientation on adolescents' autonomy and identity status. Journal of Youth and Adolescence, 39(8), 882-893.

Luyckx, K., Goossens, L., \& Soenens, B. (2006). A developmental contextual perspective on identity construction in emerging adulthood: Change dynamics in commitment formation and commitment evaluation. Developmental Psychology, 42, 366-380.

Luyckx, K., Schwartz, S. L., Goossens, L., Soenens, B., \& Beyers, W. (2008). Developmental typologies of identity formation and adjustment in female emerging adults: A latent class growth analysis approach. Journal of Research on Adolescence, 18, 595-619.

Luyckx, K., Schwartz, S. J., Soenens, B., Vansteenkiste, M., \& Goossens, L. (2010). The path from identity commitments to adjustment: Motivational underpinnings and mediating mechanisms. Journal of Counseling \& Development, 88, 52-60.

Ochse, R., \& Plug, C. (1986). Cross-cultural investigation of the validity of Erikson's theory of personality development. Journal of Personality and Social Psychology, 50, $1240-1252$.

Peacock, R., \& Theron, A. (2007). Identity development of the incarcerated adolescent with particular reference to prison gang membership. Acta Criminologia, 20(3), 61-74. 
Sandhu, D., \& Tung, S. (2006). Gender differences in adolescent identity development. Pakistan Journal of Psychological Research, 21, 29-40.

Schwartz, S. J. (2001). The Evolution of Eriksonian and neo-Eriksonian identity theory and research: A review and integration. Identity, 1, 7-58.

Schwartz, S. J., Klimstra, T.A., Luyckx, K., Hale III, W. W., Frijns, T., Oosterwegel, A. et al. (2010). Daily dynamics of identity and self-concept clarity. European Journal of Personality, 25, 373-385.

Sheldon, K. M., Elliot, A. J., Ryan, R. M., Chirkov, V., Kim, $\mathrm{Y}$., $\mathrm{Wu}, \mathrm{C}$. et al. (2004). Self-concordance and subjective well-being in four cultures. Journal of Cross-cultural Psychology, 35, 209-223.
Xia, Y. P., Xie, X., Zhou, Z., DeFrain, J., Meredith, W. H., \& Combs, R. (2004). Chinese adolescents' decision-making, parent adolescent communication and relationships. Marriage and Family Review, 36(1), 119-145.

Zimmer-Gembeck, M. J., \& Collins, W. A. (2003). Autonomy development during Adolescence. In G. R. Adams \& M. D. Berzonsky (Eds.), Blackwell handbook of adolescence (pp. 175-204). Malden, MA: Blackwell Publishing. 